\section{Outcome of patients with autoimmune diseases in the intensive care unit: a mixed cluster analysis}

Santiago Bernal-Macías, ${ }^{1,2}$ Benjamín Reyes-Beltrán, ${ }^{1,2}$ Nicolás Molano-González, ${ }^{1}$ Daniel Augusto Vega, ${ }^{2}$ Claudia Bichernall, ${ }^{2}$ Luis Aurelio Díaz, ${ }^{3}$ Adriana Rojas-Villarraga, ${ }^{1,2}$ Juan-Manuel Anaya ${ }^{1,2}$

To cite: Bernal-Macías S, Reyes-Beltrán B, MolanoGonzález N, et al. Outcome of patients with autoimmune diseases in the intensive care unit: a mixed cluster analysis. Lupus Science \& Medicine 2015;2:e000122.

doi:10.1136/lupus-2015000122

Received 22 August 2015 Revised 30 October 2015 Accepted 31 October 2015

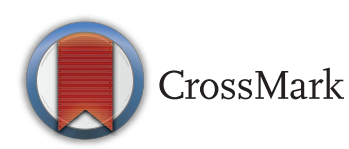

${ }^{1}$ Center for Autoimmune Diseases Research (CREA), School of Medicine and Health Sciences, Universidad del Rosario, Bogotá, Colombia

${ }^{2}$ Intensive Care Unit, Mederi, Hospital Universitario Mayor, Bogotá, Colombia

${ }^{3}$ Intensive Care Unit, Macon Lung Center, Macon, Georgia, USA

Correspondence to Professor Juan-Manuel Anaya;

anayajm@gmail.com

\section{ABSTRACT}

Objectives: The interest on autoimmune diseases (ADs) and their outcome at the intensive care unit (ICU) has increased due to the clinical challenge for diagnosis and management as well as for prognosis. The current work presents a-year experience on these topics in a tertiary hospital.

Methods: The mixed-cluster methodology based on multivariate descriptive methods such as principal component analysis and multiple correspondence analyses was performed to summarize sets of related variables with strong associations and common clinical context.

Results: Fifty adult patients with ADs with a mean age of $46.7 \pm 17.55$ years were assessed. The two most common diagnoses were systemic lupus erythematosus and systemic sclerosis, registered in $45 \%$ and $20 \%$ of patients, respectively. The main causes of admission to ICU were infection and AD flare up, observed in $36 \%$ and $24 \%$, respectively. Mortality during ICU stay was $24 \%$. The length of hospital stay before ICU admission, shock, vasopressors, mechanical ventilation, abdominal sepsis, Glasgow score and plasmapheresis were all factors associated with mortality. Two new clinical clusters variables (NCVs) were defined: Time ICU and ICU Support Profile, which were associated with survivor and no survivor variables.

Conclusions: Identification of single factors and groups of factors from NCVs will allow implementation of early and aggressive therapies in patients with ADs at the ICU in order to avoid fatal outcomes

\section{INTRODUCTION}

Autoimmune diseases (ADs) are chronic and heterogeneous conditions that affect specific target organs or multiple organ systems. These conditions share several clinical signs and symptoms, physiopathological mechanisms and genetic factors (ie, the autoimmune tautology). ${ }^{1}$ Their incidence ranges from 1 to 20 cases per 100000 person-years and the estimated prevalence is about $3 \% .^{2}$ The

\section{KEY MESSAGES}

- Morbidity and mortality in patients with autoimmune diseases seen at the intensive care unit (ICU) is still high.

- Infections and flare-up are major causes of ICU admission.

- Delay in ICU admission increases risk of mortality.

- Mixed-cluster analysis is a novel methodology establishing subgroups in real life.

impact of ADs resides in the high risk of morbidity and mortality they hold. ${ }^{3}$ The chronic nature of these diseases places a significant burden on the use of healthcare resources, which translate into elevated economic costs and low quality of life compared with the general population.

Patients with ADs may be admitted to the intensive care unit (ICU), making them a challenge to the intensivist. ${ }^{3-5}$ The prevalence of ADs in the ICU has changed in the past decades. In the past, the main ADs admitted to ICU, in order of frequency, were rheumatoid arthritis (RA), systemic lupus erythematous (SLE) and systemic vasculitis (SV). However, in the past decades SLE has been the most common AD reported. ${ }^{5}$ Mortality of patients at the ICU has been shown to be variable, ranging from $17 \%$ to $55 \% .^{5}$

Although patients with ADs may have diverse causes of admission to the ICU, acute flare of the disease and infection, mainly due to immunosuppression, is the most important. ${ }^{3-6}$ Since the expression of diseases varies depending on geography and ethnicity, and the information about ADs at the ICU in Latin America is scarce, ${ }^{37-9}$ the aim of this study was to describe factors related to mortality during ICU stay in patients with ADs assessed in a single-centre in Bogota, the capital of Colombia. 


\section{MATERIALS AND METHODS}

Study design

A retrospective case series review was performed from 1 February 2013 to 31 January 2014 for all adult patients with ADs evaluated by the Center for Autoimmune Disease Research (CREA) at the ICU in Mederi Hospital Universitario Mayor, a tertiary hospital in Bogota, Colombia. The hospital provides 828 beds, of which 120 are at the ICU (ie, medical, surgical, cardiac, neurological, others). The main general criteria for admission to the ICU are unstable conditions (ie, respiratory failure, haemodynamic collapse) or risk of an unstable condition. Every clinical record was fully evaluated to determine past medical history and outcome. Records of patients were systematically reviewed using a protocol that sought information on demographics, clinical and laboratory characteristics. Classification criteria were considered to include the following ADs: SLE, RA, SV, scleroderma (SSc), and Sjögren's syndrome (SS) ${ }^{10-15}$ Dermatopolymyositis (DPM) was classified by using Dalakas and Hohlfeld criteria. ${ }^{16}$ For antiphospholipid syndrome (APS) and autoimmune hepatitis (AIH), the 2006 updated classification criteria $^{17}$ and the international AIH group criteria ${ }^{18}$ were used, respectively. In addition, other ADs were evaluated according to the respective classification criteria (ie, autoimmune thyroid disease, AITD). ${ }^{19}$ For patients admitted more than once to ICU in the same hospitalisation, only the first ICU admission was considered.

\section{Variables}

The causes of ICU admission were classified as follows: (1) infection, (2) flare-up of $\mathrm{AD}$, (3) complications derived from the underlying $\mathrm{AD}$ (ie, cardiovascular disease (CVD)), (4) adverse effects of immunosuppressors and (5) acute serious illnesses that were unrelated to the autoimmune condition. Infection was defined as a process characterised by an inflammatory response to the presence of micro-organisms (MOs) or the invasion of normally sterile host tissue by those MOs. Sepsis and septic shock were defined in accordance with the Surviving Sepsis Campaign Guidelines 2012. ${ }^{20}$ ADs flare-up were defined as an exacerbation of a preexisting $\mathrm{AD}$ condition. ${ }^{21-26}$ Complications were acute serious illnesses that are altered or magnified by ADs. The acute conditions triggering ICU admissions were classified as follows: (1) respiratory failure, (2) haemodynamic collapse and (3) others (ie, postoperative, metabolic failure, neurological risk, risk of respiratory failure or haemodynamic collapse).

Other data recorded were age, gender, duration of disease, polyautoimmunity (ie, the presence of more than one $\mathrm{AD}$ in a single patient) including multiple autoimmune syndromes (MASs) when three or more ADs coexisted. ${ }^{27-29}$ Comorbidities, immunosuppressors in the past 3 months, the time between hospital admittance and ICU admission (ie, length of hospital stay before ICU admission), length of ICU stay, the need of intensive care support (ie, mechanical ventilation (MV), vasopressor support, dialysis, plasmapheresis, blood transfusion) and the reduction in left ventricular ejection fraction using the definition available from American Heart Association for heart failure ${ }^{30}$ were also variables registered. Pulmonary hypertension corresponded to a pulmonary arterial systolic pressure $>50 \mathrm{~mm} \mathrm{Hg}$ measured by transthoracic echocardiography. ${ }^{31}$ Abnormal acid-base blood balance was also recorded and dichotomised as normal or abnormal based on the Siggaard-Andersen nomogram. ${ }^{32}$ The classification of Vincent $e t a \hat{l}^{3}$ was used for shock. Other variables recorded were the Acute Physiology and Chronic Health Evaluation II (APACHE II) score, ${ }^{34}$ the organ dysfunctions and/or infection score ${ }^{35}$ the sequential organ failure assessment score (SOFA), ${ }^{36}$ the $\mathrm{PaO}_{2}$ : $\mathrm{FiO}_{2}$ ratio of arterial oxygen tension to inspired oxygen concentration according to the values for Acute Respiratory Distress Syndrome ${ }^{37}$ and the Glasgow scale. ${ }^{38}$ Finally, the treatment of $\mathrm{AD}$ during ICU was also registered.

\section{Statistical analysis}

The mixed-cluster methodology proposed by Lebart et $a l^{39}$ based on multivariate descriptive methods such as principal component analysis and multiple correspondence analysis was performed to summarise sets of related variables with strong associations and common clinical context. Thus, by means of this clustering technique, for each set of related variables, new cluster variables (NCVs) were derived. For example, length of hospital stay before ICU admission and length of ICU stay, two variables with a non-linear relation, yielded a NCV (ie, 'Time ICU') which corresponds to a categorical variable with three outcomes (see results).

The $\chi^{2}$ and Fisher's exact tests were performed to established differences between categorical variables (original and NCV) and mortality. Kruskal-Wallis test was performed for assessing possible differences in continuous variables on mortality status. Statistical analysis was performed in R 3.0.2. ${ }^{40}$

\section{RESULTS}

During the time period study (ie, February 2013 to January 2014), 485 hospitalised patients were evaluated by the CREA, of whom 79 were seen at the ICU. Of these, 50 were selected for analysis as they fulfilled the inclusion criteria of $\mathrm{AD}$, the other 29 patients were excluded because they did not fulfil the classification criteria of $\mathrm{AD}$.

Baseline patient characteristics are shown in table 1 . Most of the patients were women $(78 \%)$. The mean duration of ADs was $49.43 \pm 79.48$ months (data were missing in three patients), and the mean length of stay in ICU was $10.96 \pm 11.06$ days. The most frequent ADs were SLE, SSc and RA observed in $46 \%, 20 \%$ and $18 \%$, respectively (table 2). There were 13 patients (26\%) with 
Table 1 Characteristics of patients with ADs admitted to the ICU

\begin{tabular}{|c|c|c|c|c|c|}
\hline Characteristic & $\begin{array}{l}\text { Total } \\
n=50\end{array}$ & $\begin{array}{l}\text { Survivors } \\
n=38(76 \%)\end{array}$ & $\begin{array}{l}\text { No survivors } \\
\mathrm{n}=12(24 \%)\end{array}$ & p Value & OR $(95 \% \mathrm{Cl})$ \\
\hline Age (years) & $46.7 \pm 17.55$ & $46.23 \pm 18.58$ & $48.17 \pm 14.39$ & NS & \\
\hline Gender, female (\%) & $39(78 \%)$ & $30(78.9 \%)$ & $9(75 \%)$ & NS & \\
\hline Length of hospital stay before ICU (days) & $6.82 \pm 9.61$ & $4.65 \pm 8.13$ & $13.67 \pm 11.03$ & 0.002 & \\
\hline Length of ICU stay (days) & $10.96 \pm 11.06$ & $11.5 \pm 11.85$ & $9.25 \pm 8.29$ & NS & \\
\hline Re-entry ICU & $6(12 \%)$ & $5(13.16 \%)$ & $1(8.33 \%)$ & NS & \\
\hline Death during ICU stay & $12(24 \%)$ & - & - & & \\
\hline Death during hospitalisation after ICU & $4(8 \%)$ & $4(10.5 \%)$ & - & & \\
\hline Hospital readmission & $5(10 \%)$ & $5(13.2 \%)$ & - & & \\
\hline \multicolumn{6}{|l|}{$A D$-related factors } \\
\hline Duration of $A D$ (months)* & $49.43 \pm 79.48$ & $47.75 \pm 84.79$ & $54.91 \pm 62.02$ & 0.3822 & \\
\hline New diagnosis & $11(22 \%)$ & $8(22.2 \%)$ & $3(25 \%)$ & NS & \\
\hline \multicolumn{6}{|l|}{ Previous comorbidity } \\
\hline No disease background & $16(32 \%)$ & $12(31.6 \%)$ & $4(33.3 \%)$ & NS & \\
\hline New diagnosis $A D$ & $5(31.25 \%)$ & $4(33.3 \%)$ & $1(25 \%)$ & NS & \\
\hline Previously diagnosis AD & $11(68.75 \%)$ & $8(66.7 \%)$ & $3(75 \%)$ & NS & \\
\hline Cardio and cerebrovascular disease & $18(36 \%)$ & $15(39.5 \%)$ & $3(25 \%)$ & NS & \\
\hline Chronic kidney disease & $13(26 \%)$ & $12(31.6 \%)$ & $1(8.3 \%)$ & NS & \\
\hline \multicolumn{6}{|l|}{ Prior immunosuppressant within 3 months } \\
\hline No pharmacology background & $15(30 \%)$ & $12(31,6 \%)$ & $3(25 \%)$ & NS & \\
\hline Steroids & $33(66 \%)$ & $24(63.2 \%)$ & $9(75 \%)$ & NS & \\
\hline Other immunosuppressors $†$ & $22(44 \%)$ & $15(39.5 \%)$ & $7(58.3 \%)$ & NS & \\
\hline \multicolumn{6}{|l|}{ ICU parameters } \\
\hline$A P A C H E ~ / I(n=42)$ & $14.07 \pm 7.02$ & $13.53 \pm 7.47$ & $15.8 \pm 5.25$ & 0.2737 & \\
\hline ODIN score & $2.48 \pm 1.57$ & $2.26 \pm 1.52$ & $3.18 \pm 1.59$ & 0.1041 & \\
\hline Glasgow score & $12.94 \pm 3.21$ & $13.65 \pm 2.48$ & $10.67 \pm 4.21$ & 0.043 & \\
\hline Severe Glasgow score & $7(14 \%)$ & $2(5.26 \%)$ & $5(41.6 \%)$ & 0.005 & $11.5(1.71$ to 77.18$)$ \\
\hline Complication during ICU stay§ & $7(14 \%)$ & $2(5.3 \%)$ & $5(41.7 \%)$ & 0.002 & 7.50 (1.97 to 57.96$)$ \\
\hline MV & $26(52 \%)$ & $15(39.5 \%)$ & $11(91.67 \%)$ & 0.002 & $7.91(1.88$ to 71.61$)$ \\
\hline \# days MV & $4.24 \pm 8.49$ & $3.53 \pm 8.53$ & $6.5 \pm 8.32$ & 0.037 & \\
\hline Dialysis & $11(22 \%)$ & $10(26.3 \%)$ & $1(8.3 \%)$ & NS & \\
\hline CPR & $13(26 \%)$ & $2(5.3 \%)$ & $11(91.7 \%)$ & $<10^{-4}$ & $66.0(13.30$ to 948.89$)$ \\
\hline Transfusion & $35(70 \%)$ & $24(63.2 \%)$ & $11(91.7 \%)$ & NS & \\
\hline Vasopressor support & $26(52 \%)$ & $16(42.1 \%)$ & $10(83.3 \%)$ & 0.013 & 4.31 (1.25 to 26.14$)$ \\
\hline Shock & $26(52 \%)$ & $16(42.1 \%)$ & $10(83.3 \%)$ & 0.013 & $4.31(1.25$ to 26.14$)$ \\
\hline Alveolar haemorrhage & $10(20 \%)$ & $9(23.7 \%)$ & $1(8.3 \%)$ & NS & \\
\hline IVIG ICU & $19(38 \%)$ & $16(42.1 \%)$ & $3(25 \%)$ & NS & \\
\hline Plasmapheresis ICU & $10(20 \%)$ & $5(13.2 \%)$ & $5(41.7 \%)$ & 0.031 & 3.44 (1.07 to 18.52$)$ \\
\hline ICU support NCV $(n=38)^{\star *}$ & $14(36.8 \%)$ & $3(11.5 \%)$ & $11(91.6 \%)$ & $<10^{-4}$ & $31.63(6.70$ to 395.34$)$ \\
\hline \multicolumn{6}{|l|}{ Infections } \\
\hline Sepsis & $33(66 \%)$ & $24(63.2 \%)$ & $9(75 \%)$ & NS & \\
\hline Septic shock & $18(36 \%)$ & $11(28.9 \%)$ & $7(58.3 \%)$ & NS & \\
\hline
\end{tabular}




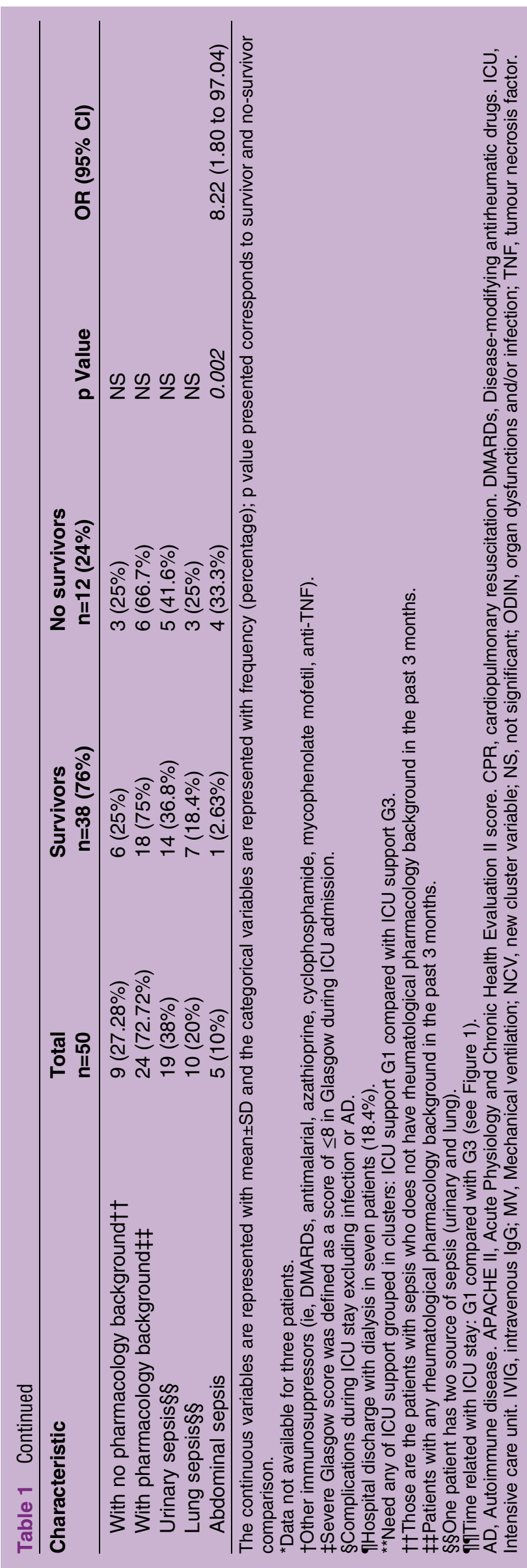

polyautoimmunity, of whom $4(8 \%)$ had MAS. Eleven patients were newly diagnosed as having AD during hospitalisation.

Twelve patients (24\%) did not survive during ICU stay and their causes of death were sepsis in five, intracerebral haemorrhages in two and upper gastrointestinal bleeding, cardiac tamponade and hemoperitoneum secondary to kidney biopsy in each one. In two patients the cause of death was not determined.

Sixteen patients $(32 \%)$ did not have a previous comorbidity. Conversely, 13 patients $(26 \%)$ had chronic kidney disease and 18 patients (36\%) had CVD. Most of the patients were on steroids $(n=33(66 \%))$. Otherwise, disease-modifying antirheumatic drugs (DMARDs) were registered in nine patients $(18 \%)$, antimalarial in eight patients (16\%), immunosuppressors (ie, azathioprine, cyclophosphamide, mycophenolate mofetil) in eight $(16 \%)$, and three $(6 \%)$ patients were on anti-tumour necrosis factor drugs (ie, adalimumab, etanercept and infliximab, respectively).

Infection was the most frequent $(36 \%)$ cause of admission. Thirteen patients presented with septic shock as the cause of ICU admission (table 2). Total sepsis events were observed in 33 patients $(66 \%)$. Seventeen patients become infected after ICU admission, and five patients developed septic shock after ICU admission. Urinary tract infection and pneumonia were the most frequent infections observed during ICU stay, and were the most frequent cause of sepsis (38\% and 20\%, respectively). Abdominal sepsis was registered in five cases (ie, gastrointestinal and gynaecological), of which four cases were associated with urinary tract infection and pneumonia. Two cases had infective endocarditis. Septicaemia without identifiable source was registered in two cases. In summary, 21 patients had one source of sepsis and 12 patients had two sources of sepsis due to different MOs.

The use of intravenous IgG (IVIG) and plasmapheresis was more frequent than the use of immunosuppressors (ie, cyclophosphamide and anti-CD20 monoclonal antibodies) as treatment for disease flare-ups.

Factors associated with poor outcome (ie, death) were length of hospitalisation before entry to ICU, low Glasgow scores and length of MV (table 1). In the survivor group, seven patients (18.4\%) were discharged on haemodialysis and four patients $(10.5 \%)$ deceased after ICU discharge. Five patients $(13.2 \%)$ were readmitted to the hospital before 30 days of discharge.

Two significant NCVs where found. First NCV was 'Time ICU' derived from length of hospital stay before ICU admission and length of ICU stay variables, which provided in turn three groups (figure 1). The second NCV was 'ICU support profile', derived from cluster analysis on outcomes of MV, non-invasive MV, cardiopulmonary resuscitation, vasopressor support, transfusion and dialysis variables. From this NCV, four groups where obtained (figure 2).

For these two NCV we found that in Time ICU-G1 (short total ICU stay and long hospital stay before ICU 


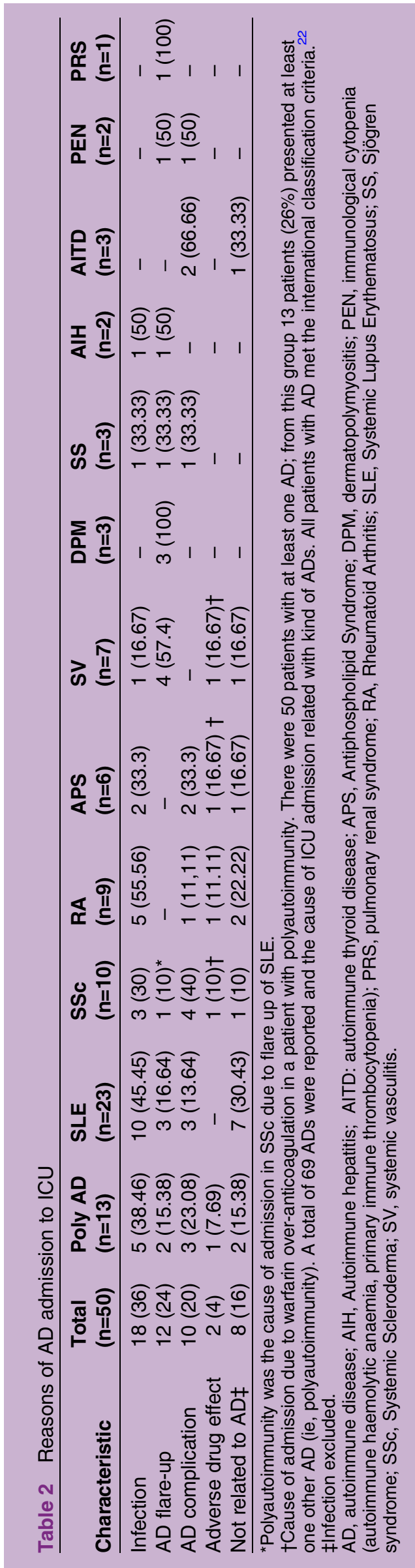

admission) was associated with a higher risk of death in relation to Time ICU-G3 (short hospital stay before ICU and during ICU). Although this finding is explained by the association between mortality and long hospital stay before ICU admission (see table 1), this cluster analysis shows an interesting relation between total ICU stay and hospital stay before ICU admission. There were no patients with long duration on both variables. Patients in our study disclosed a long hospital stay before ICU admission and short ICU stay or vice versa. Similarly, ICU support-G1 (high presence of all the studied supports except non-invasive MV and dialysis) was associated with higher risk of death in relation to ICU support-G3 (little support needed) (table 1).

\section{DISCUSSION}

The present study shows the 1-year characteristics and a mixed-cluster analysis of patients with ADs who required admittance to the ICU in a referral hospital in Bogota, Colombia. The most common diagnosis in our series was SLE, as has been already reported. ${ }^{378}$ However, the second $\mathrm{AD}$ was $\mathrm{SSc}$, a result differing from previous studies. ${ }^{3}{ }^{3} 6-8 \quad 41$ Although polyautoimmunity was frequently registered (26\%), no significant influence of this condition on outcome was observed in this study. Our results indicate that in spite of the great progress on ICU resources and a better understanding of autoimmunity, there is still a high morbidity and mortality in patients with ADs seen at the ICU.

Known factors associated with mortality in patients with ADs admitted to the ICU are APACHE II, SOFA, length of stay, shock, comorbidities, vasopressors or immunosuppressive drugs. ${ }^{3}{ }^{6} 7^{41-44}$ In our case series, the length of hospital stay before ICU admission, shock, vasopressors, MV, abdominal sepsis, Glasgow score and plasmapheresis were all factors associated with mortality.

Noteworthy, instead of considering each variable separately, we introduce the construction of NCVs as a novel methodology with the goal of establishing relevant clinical variables present together in a patient, since clinical manifestations do not appear isolated but rather in conjunction with others. With this approach, subgroups are identified allowing clinicians to better manage patients in real-life conditions. ${ }^{45}$

Previous studies and ours have identified that long hospital stay before ICU admission is a survival risk factor for patients with ADs. ${ }^{5} 43$ A delay in recognising patients with unstable conditions may worsen their survival rate. Thus, it is important to establish early detection programmes to identify patients at risk of mortality. ${ }^{20}$

The ICU support profile NCV disclosed four groups and represents life support manoeuvres (figure 2) used in the ICU. Some of these manoeuvres were already evaluated as individual variables; however, this analysis represent the interaction of groups of life support and the needed of life support due to organ failure (ie, 
Figure 1 New cluster variable

Time ICU. Within this cluster, three groups are observed, namely G1, G2 and G3. G1 was characterised by a short total ICU stay and long hospital stay before ICU admission. G2 had an opposite trend of that found in $\mathrm{G} 1$, that is, long total ICU stay and short hospital stay before ICU admission. Finally, G3 was related with short hospital stays before ICU and during ICU. Total days in ICU refers to the length of stay at ICU regardless the number of re-entries; Days before ICU admission refers to the length of hospital stay before ICU admission. ICU, Intensive care unit.

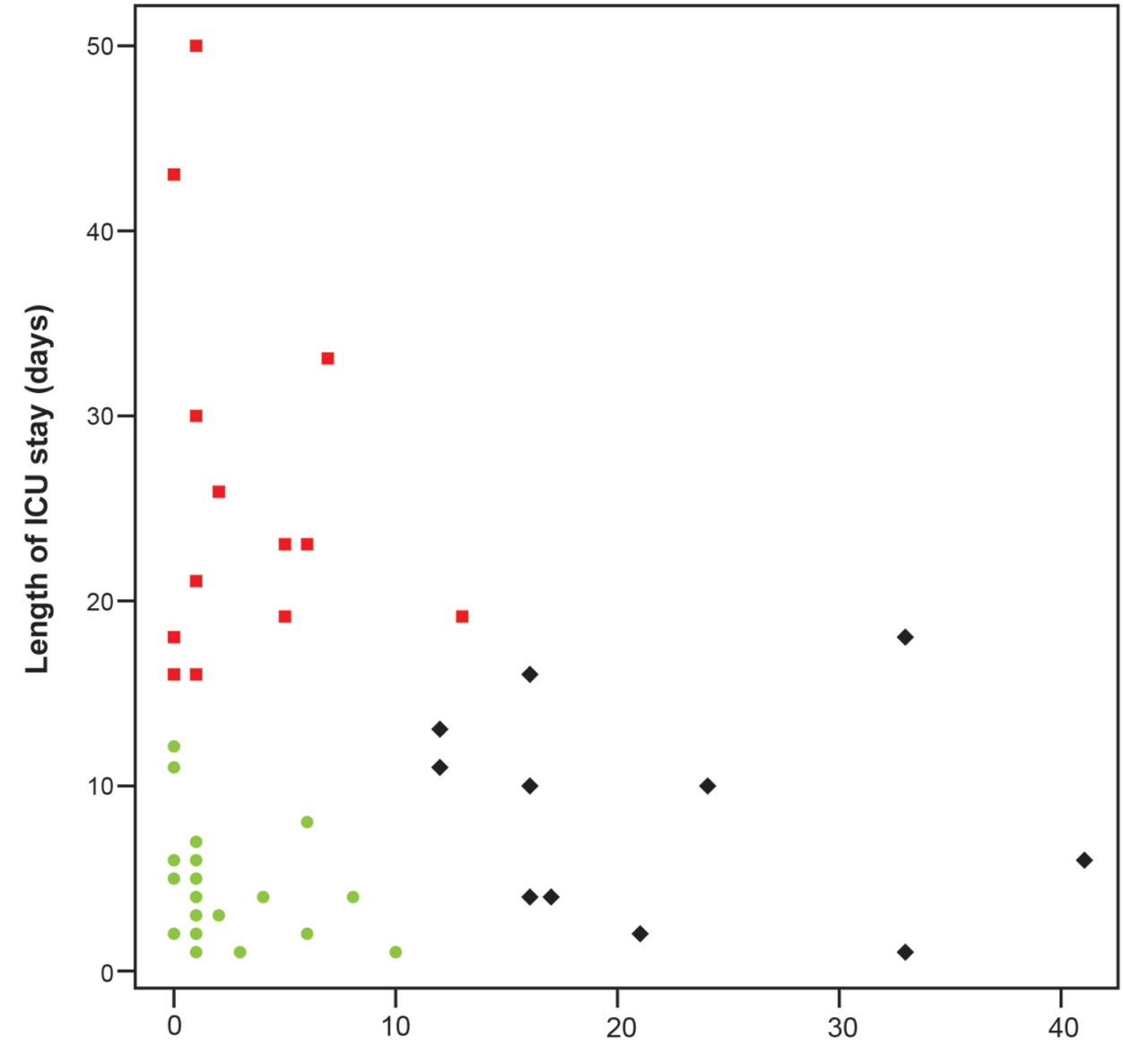

Length of hospital stay before ICU (days)

\begin{tabular}{|l|l|l|}
\hline \multirow{2}{*}{ Group 1 } & Higher & Days before ICU admission \\
\cline { 2 - 3 } & Lower & Days in ICU \\
\hline \multirow{2}{*}{ Group 2 } & Higher & Days in ICU \\
\cline { 2 - 3 } & Lower & Days before ICU admission \\
\hline Group 3 & Lower & $\begin{array}{l}\text { Days before ICU admission; Days in } \\
\text { ICU }\end{array}$ \\
\hline
\end{tabular}

worst prognosis). ${ }^{3} 424446$ Plasmapheresis is a valuable treatment option for critically ill patients suffering antibody-mediated illness such as ADs and has been considered a relatively safe treatment of ICU patients. ${ }^{47} 48$ In the present case series plasmapheresis was associated with mortality, denoting severity of illness. Thus, this association should be considered as a bias (ie, confounding by indication).

Comorbidities in patients with ADs should be recognised as early as possible and treated promptly in the hope of avoiding systemic complications. ${ }^{3-5} 49$ Some important comorbidities such as CVD and chronic renal disease have a bad impact on the quality of life, patients' survival and, as expected, increases the economic burden of disease. ${ }^{50}$ Nevertheless, in the present study comorbidities were not associated with mortality. 
A

ICU support
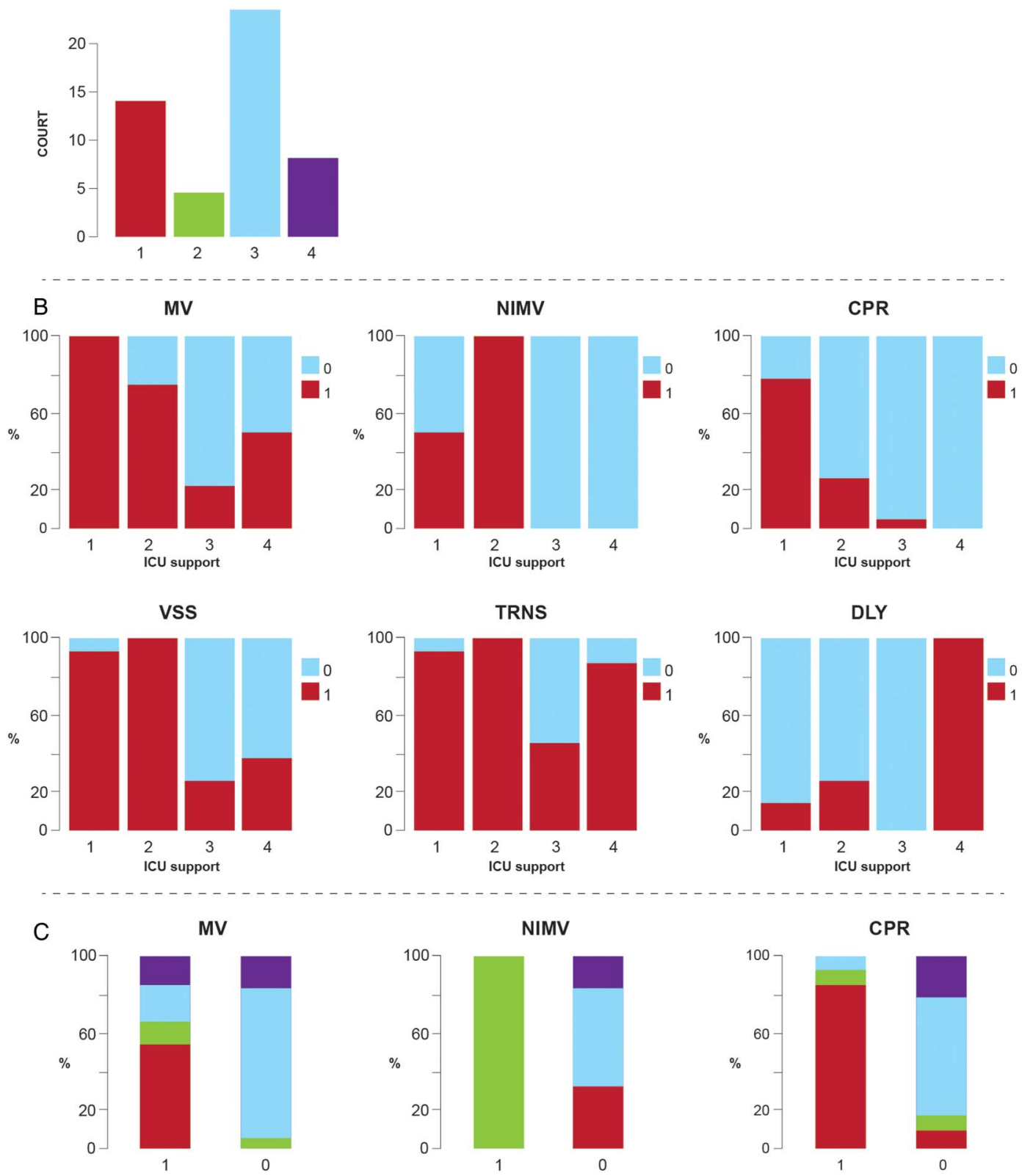

vss

TRNS

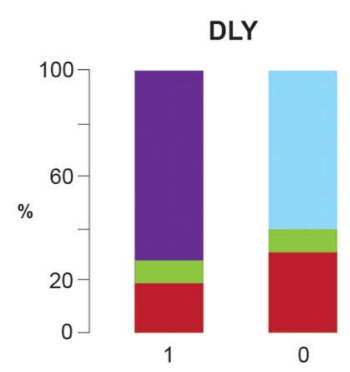

Figure 2 'ICU support profile' cluster. From this new cluster variable, four groups where obtained (A): (1) ICU support-G1, associated with high presence of all the studied supports except non-invasive mechanical ventilation and some sporadic dialysis; (2) ICU support-G2, associated with high presence of all the studied supports except CPR and DLY; (3) ICU support-G3, related with patients for whom little if any support was needed, and (4) ICU support-G4, associated with those patients requiring DLY and transfusion together with very few outcomes in other supports. (B) Profile of each group with respect to the original variables used to build the groups. (C) Profile of each original variable in terms of groups' composition. 1: presence of the variable, 0 : absence of the variable. CPR, cardiopulmonary resuscitation; MV, mechanical ventilation; NIMV, non-invasive MV; VSS, vasopressor support; TRNS, blood transfusion; DLY, dialysis. 
Table 3 ADs at the ICU (revision of the literature)

\begin{tabular}{|c|c|c|c|c|c|c|c|c|}
\hline $\begin{array}{l}\text { Author } \\
\text { (reference) }\end{array}$ & Year & No. & $\begin{array}{l}\text { In-ICU } \\
\text { mortality (\%) }\end{array}$ & $\begin{array}{l}\text { Infection } \\
(\%)\end{array}$ & $\begin{array}{l}\text { AD } \\
\text { flare-up } \\
(\%)\end{array}$ & $\begin{array}{l}\text { AD } \\
\text { complication } \\
(\%)\end{array}$ & $\begin{array}{l}\text { Adverse drug } \\
\text { effect (\%) }\end{array}$ & $\begin{array}{l}\text { Not related } \\
\text { to AD (\%) }\end{array}$ \\
\hline Godeau et $\mathrm{al}^{50}$ & 1992 & 69 & 33 & 42 & 28 & NR & NR & 17 \\
\hline Kollef et $a^{41}$ & 1992 & 36 & 31 & NR & NR & NR & NR & NR \\
\hline Bouachour et al ${ }^{46}$ & 1996 & 88 & 38 & 31 & 32 & NR & NR & 23 \\
\hline Godeau et $\mathrm{al}^{6}$ & 1997 & 181 & 33 & 41 & 28 & NR & 18 & 13 \\
\hline Pourrat et $a l^{51}$ & 2000 & 33 & 30 & 33 & 26 & NR & NR & NR \\
\hline Thong et $a^{44}$ & 2001 & 28 & 54 & 64 & NR & NR & NR & NR \\
\hline Moreels et $a l^{41}$ & 2003 & 71 & 32 & 30 & NR & NR & NR & NR \\
\hline Camargo et $a l^{3}$ & 2005 & 24 & 17 & 38 & 38 & 29 & 17 & 25 \\
\hline Coral et $a l^{8}$ & 2006 & 18 & 55 & 27 & 44 & 22 & 5 & NR \\
\hline Cavallasca et $\mathrm{al}^{7}$ & 2010 & 31 & 55 & 35 & 23 & NR & NR & 13 \\
\hline Anton et $a l^{53}$ & 2012 & 37 & 19 & 32 & 54 & NR & NR & NR \\
\hline Faguer et al ${ }^{52}$ & 2013 & 149 & 16 & 47 & 48 & NR & NR & 11 \\
\hline Current study & 2014 & 50 & 24 & 36 & 24 & 20 & 4 & 16 \\
\hline
\end{tabular}

the ICU unit and were not consider into the ICU nonsurvivor group. Sample size precludes any inference of causality in the links between ICU mortality and related factors. Despite the meticulous study design, which was employed to control for confounding factors, the relation between plasmapheresis and non-survival could be attributed to confounding by indication due to hospital protocol.

\section{CONCLUSION}

We report a novel analysis of the outcome of patients with ADs admitted to the ICU. Detection of single factors and groups of factors from NCVs will allow implementation of early and aggressive therapies in order to avoid fatal outcomes.

Acknowledgements The authors thank their colleagues at the Center for Autoimmune Diseases Research as well as Dario Pinilla and colleagues from the Mederi Intensive Care Unit at Mederi Hospital Universitario Mayor for their fruitful discussions and contributions to this work

Contributors All the authors certifies that neither this manuscript nor the one with substantially similar content under our authorship has been published or is being considered for publication elsewhere (except as indicated in an attachment). We agree to allow the corresponding author to correspond with the editorial office to review the uncorrected proof copy of the manuscript and to make decisions regarding the release of information in the manuscript. The authors have given final approval of the submitted manuscript for which they take public responsibility for whole content.

Competing interests None declared.

Ethics approval Ethics Committee School of Medicine and Health Sciences, Universidad del Rosario, Bogotá, Colombia.

Provenance and peer review Not commissioned; externally peer reviewed.

Data sharing statement The authors have access to any data on which the manuscript is based and will provide such data on request to the editors or their assignees.

Open Access This is an Open Access article distributed in accordance with the Creative Commons Attribution Non Commercial (CC BY-NC 4.0) license, which permits others to distribute, remix, adapt, build upon this work noncommercially, and license their derivative works on different terms, provided the original work is properly cited and the use is non-commercial. See: http:// creativecommons.org/licenses/by-nc/4.0/

\section{REFERENCES}

1. Anaya J-M, Shoenfeld $Y$, Rojas-Villarraga A, et al., eds Autoimmunity from bench to bedside. Editorial Universidad del Rosario. Bogotá, 2013.

2. Cooper GS, Stroehla BC. The epidemiology of autoimmune diseases. Autoimmun Rev 2003;2:119-25.

3. Camargo J, Tobón G, Fonseca N, et al. Autoimmune rheumatic diseases in the intensive care unit: experience from a tertiary referral hospital and review of the literature. Lupus 2005;14:315-20.

4. Janssen NM, Karnad DR, Guntupalli KK. Rheumatologic diseases in the intensive care unit: epidemiology, clinical approach, management, and outcome. Crit Care Clin 2002;18:729-48.

5. Quintero OL, Rojas-Villarraga A, Mantilla RD, et al. Autoimmune diseases in the intensive care unit. An update. Autoimmun Rev 2013;12:380-95.

6. Godeau B, Mortier E, Roy PM, et al. Short and long-term outcomes for patients with systemic rheumatic diseases admitted to intensive care units: a prognostic study of 181 patients. J Rheumatol 1997;24:1317-23

7. Cavallasca JA, Del Rosario Maliandi M, Sarquis S, et al. Outcome of patients with systemic rheumatic diseases admitted to a medical intensive care unit. J Clin Rheumatol 2010;16:400-2.

8. Coral P, Diaz M, Chalem M, et al. Outcome of patients with rheumatic diseases that requires attention in the medical intensive care unit. J Clin Rheumatol 2006;12:S77-8.

9. Cairoli E. Unidades de enfermedades autoinmunes sistémicas: notas de una experiencia en curso. Rev Médica Urug 2013;29:248-9.

10. Hochberg MC. Updating the American College of Rheumatology revised criteria for the classification of systemic lupus erythematosus. Arthritis Rheum 1997;40:1725.

11. Van den Hoogen F, Khanna D, Fransen J, et al. 2013 classification criteria for systemic sclerosis: an American College of

Rheumatology/European League against Rheumatism collaborative initiative. Arthritis Rheum 2013;65:2737-47.

12. Arnett FC, Edworthy SM, Bloch DA, et al. The American Rheumatism Association 1987 revised criteria for the classification of rheumatoid arthritis. Arthritis Rheum 1988;31: 315-24.

13. Vitali C, Bombardieri S, Jonsson R, et al. Classification criteria for Sjögren's syndrome: a revised version of the European criteria proposed by the American-European Consensus Group. Ann Rheum Dis 2002;61:554-8.

14. Jennette JC, Falk RJ, Bacon PA, et al. 2012 revised International Chapel Hill Consensus Conference Nomenclature of Vasculitides. Arthritis Rheum 2013;65:1-11.

15. Hunder GG, Arend WP, Bloch DA, et al. The American College of Rheumatology 1990 criteria for the classification of vasculitis. Introduction. Arthritis Rheum 1990;33:1065-7.

16. Dalakas MC, Hohlfeld R. Polymyositis and dermatomyositis. Lancet 2003;362:971-82.

17. Miyakis S, Lockshin MD, Atsumi T, et al. International consensus statement on an update of the classification criteria for definite 
antiphospholipid syndrome (APS). J Thromb Haemost 2006;4:295-306

18. Hennes EM, Zeniya M, Czaja AJ, et al. Simplified criteria for the diagnosis of autoimmune hepatitis. Hepatology 2008;48:169-76. 10

19. Rojas-Villarraga A, Toro CE, Espinosa G, et al. Factors influencing polyautoimmunity in systemic lupus erythematosus. Autoimmun Rev 2010;9:229-32.

20. Dellinger RP, Levy MM, Rhodes A, et al. Surviving sepsis campaign: International Guidelines for management of severe sepsis and septic shock: 2012. Crit Care Med 2013;41:580-637.

21. Gladman DD, Ibañez D, Urowitz MB. Systemic lupus erythematosus disease activity index 2000. Systemic Lupus Erythematosus Disease Activity Index 2000. J Rheumatol 2002;29:288-91.

22. Prevoo M, van't Hof M, Kuper $\mathrm{H}$, et al. Modified disease activity scores that include twenty-eight-joint counts. Arthritis Rheum 1995;38:44-8.

23. Bose N, Chiesa-Vottero A, Chatterjee S. Scleroderma renal crisis. Semin Arthritis Rheum 2015;44:687-94.

24. Alexanderson $\mathrm{H}$, Lundberg IE. Disease-specific quality indicators, outcome measures and guidelines in polymyositis and dermatomyositis. Clin Exp Rheumatol 2007;25(6 Suppl 47):153-8.

25. Ramos-Casals M, Tzioufas AG, Stone $\mathrm{JH}$, et al. Treatment of primary Sjögren syndrome: a systematic review. JAMA 2010;304:452-60.

26. Rodríguez-Pintó I, Soriano A, Espinosa G, et al. Catastrophic antiphospholipid syndrome: an orchestra with several musicians. Isr Med Assoc J 2014;16:585-6.

27. Anaya JM. The diagnosis and clinical significance of polyautoimmunity. Autoimmun Rev 2014;13:423-6.

28. Rojas-Villarraga A, Amaya-Amaya J, Rodriguez-Rodriguez A, et al. Introducing polyautoimmunity: secondary autoimmune diseases no longer exist. Autoimmune Dis 2012:2012:254319.

29. Anaya JM, Castiblanco J, Rojas-Villarraga A, et al. The multiple autoimmune syndromes. A clue for the autoimmune tautology. Clin Rev Allergy Immunol 2012;43:256-64.

30. Yancy CW, Jessup M, Bozkurt B, et al. 2013 ACCF/AHA guideline for the management of heart failure: a report of the American College of Cardiology Foundation/American Heart Association Task Force on practice guidelines. Circulation 2013;128: e240-319.

31. Galiè N, Hoeper MM, Humbert M, et al. Guidelines for the diagnosis and treatment of pulmonary hypertension: the Task Force for the Diagnosis and Treatment of Pulmonary Hypertension of the European Society of Cardiology (ESC) and the European Respiratory Society (ERS), endorsed by the Internat. Eur Heart $J$ 2009;30:2493-537.

32. Siggaard-Andersen O. Acid-base balance. In Encyclopedia of Respiratory Medicine, 2005:1-6.

33. Vincent J, De Backer D. Circulatory shock. N Engl J Med 2013;369:1726-34

34. Knaus W, Draper E, Wagner D, et al. APACHE II: a severity of disease classification system. Crit Care Med 1985;13:818-29.

35. Fagon J, Chastre J, Novara A, PM, et al. Intensive Care Medicine Characterization of intensive care unit patients using a model based on the presence or absence of organ dysfunctions and/or infection: the ODIN model. Intensive Care Med 1993;19:137-44. 11.

36. Moreno R, Vincent J, Matos $\mathrm{R}$, et al. The use of maximum SOFA score to quantify organ dysfunction/failure in intensive care. Results of a prospective, multicentre study. Intensive Care Med 1999:25:686-96.

37. Ranieri VM, Rubenfeld GD, Thompson BT, et al. Acute respiratory distress syndrome: the Berlin Definition. JAMA 2012;307:2526-33.
38. Teasdale G, Jennett B. Assessment of coma and impaired consciousness. Lancet 1974;13:81-4.

39. Lebart L, Morineau A, Piron M. Statistique exploratoire multidimensionnelle. Paris, Dunod; 1995.

40. R Development Core Team. R: a language and environment for statistical computing. 011

41. Kollef MH, Enzenauer RJ. Predicting outcome from intensive care for patients with rheumatologic diseases. $J$ Rheumatol 1992;19:1260-2.

42. Moreels M, Mélot C, Leeman M. Prognosis of patients with systemic rheumatic diseases admitted to the intensive care unit. Intensive Care Med 2005;31:591-3.

43. Alzeer AH, Al-Arfaj A, Basha SJ, et al. Outcome of patients with systemic lupus erythematosus in intensive care unit. Lupus 2004;13:537-42.

44. Thong BY, Tai DY, Goh SK, et al. An audit of patients with rheumatic disease requiring medical intensive care. Ann Acad Med Singapore 2001;30:254-9.

45. Van der Esch M, Knoop J, van der Leeden M, et al. Clinical phenotypes in patients with knee osteoarthritis: a study in the Amsterdam osteoarthritis cohort. Osteoarthr Cartil 2015;23:544-9.

46. Bouachour G, Roy PM, Tirot P, et al. [Prognosis of systemic diseases diagnosed in intensive care units]. Presse Med 1996;25:837-41.

47. Paton E, Baldwin IC. Plasma exchange in the intensive care unit: a 10 year retrospective audit. Aust Crit Care 2014;27:139-44.

48. Szczeklik W, Wawrzycka K, Włudarczyk A, et al. Complications in patients treated with plasmapheresis in the intensive care unit. Anaesthesiol Intensive Ther 2013;45:7-13.

49. Amaya-Amaya J, Montoya-Sánchez L, Rojas-Villarraga A. Cardiovascular involvement in autoimmune diseases. Biomed Res Int 2014;2014:367359.

50. Godeau B, Boudjadja A, Dhainaut J, et al. Outcome of patients with systemic rheumatic disease admitted to medical intensive care units. Ann Rheum Dis 1992;51:627-31.

51. Pourrat O, Bureau JM, Hira M, et al. [Outcome of patients with systemic rheumatic diseases admitted to intensive care units: a retrospective study of 39 cases]. Rev Med Interne 2000;21:147-51.

52. Faguer S, Ciroldi M, Mariotte E, et al. Prognostic contributions of the underlying inflammatory disease and acute organ dysfunction in critically ill patients with systemic rheumatic diseases. Eur J Intern Med 2013;24:e40-4.

53. Anton JM, Castro P, Espinosa G, et al. Mortality and long term survival prognostic factors of patients with systemic autoimmune diseases admitted to an intensive care unit: a retrospective study. Clin Exp Rheumatol 2012;30:338-44.

54. Doria A, Canova M, Tonon M, et al. Infections as triggers and complications of systemic lupus erythematosus. Autoimmun Rev 2008;8:24-8.

55. Avcin T, Canova M, Guilpain $\mathrm{P}$, et al. Infections, connective tissue diseases and vasculitis. Clin Exp Rheumatol 26(1 Suppl 48): S18-26.

56. Girschick HJ, Guilherme L, Inman RD, et al. Bacterial triggers and autoimmune rheumatic diseases. Clin Exp Rheumatol 26(1 Suppl 48):S12-7. 12

57. Ortiz G, Dueñas $C$, Rodríguez F, et al. Epidemiology of sepsis in Colombian Intensive care units. Biomedica 2014;34:40-7.

58. Pandharipande PP, Girard TD, Jackson JC, et al. Long-term cognitive impairment after critical illness. $N$ Engl J Med 2013;369:1306-16.

59. Wilcox ME, Brummel NE, Archer K, et al. Cognitive dysfunction in ICU patients: risk factors, predictors, and rehabilitation interventions. Crit Care Med 2013; 41(9 Suppl 1):S81-98. 